\title{
The influence of SnoN gene silencing by siRNA on the cell proliferation and apoptosis of human pancreatic cancer cells
}

\author{
Chengli Liu ${ }^{1 *}$, Hui Zhang ${ }^{1}$, Xiaoxia Zang ${ }^{2}$, Cheng Wang ${ }^{1}$, Yalin Kong ${ }^{1}$ and Hongyi Zhang ${ }^{1}$
}

\begin{abstract}
Background: The prognosis for pancreatic cancer $(P C)$ is very poor. The SnoN gene may have a role in cell proliferation and apoptosis in human cancer. However, the influence of $\mathrm{SnON}$ on cell proliferation and apoptosis in human PC cells remains unknown.

Methods: SnoN expression was assessed in SW1990 PC cell lines using real-time polymerase chain reaction (PCR). A luciferase reporter assay was used to confirm the target associations. The effect of SnoN on cell proliferation in vitro was confirmed using Cell Counting Kit-8. Apoptosis was confirmed using flow cytometry. Gene and protein expression were examined using real time PCR and Western blotting, respectively.

Results: SnoN siRNA significantly inhibited the growth of SW1990 cells by decreasing cell proliferation $(P<0.05)$ and increasing cell apoptosis $(P<0.05)$, compared with the blank group and the negative control group. The highest inhibition of cell proliferation appeared at 3 days post-transfection. Cell apoptosis more obvious at $48 \mathrm{~h}$ after transfection.

Conclusions: In summary, our results reveal that the RNAi-mediated downregulation of SnoN effectively inhibited the proliferation of PC cells. SnoN-siRNA also enhanced SW1990 PC cell apoptosis. These findings indicate that SnoN gene plays an important role in pancreatic cancer development, and might serve as a potential therapeutic target for pancreatic cancer. However, further in vivo studies are needed to clarify the influence of SnoN gene silencing by siRNA on pancreatic cancer therapy.

Virtual slides: The virtual slide(s) for this article can be found here: http://www.diagnosticpathology.diagnomx. eu/vs/7609324661510147
\end{abstract}

Keywords: SnoN gene, Proliferation, Apoptosis, Pancreatic cancer (PC)

\section{Background}

Pancreatic cancer (PC) is one of the most fatal malignant diseases worldwide. The incidence of PC is lower than that of many other types of cancer. However, it is the fourth most common cause of death from cancer [1]. Because of nonspecific incipient symptoms and early metastasis, $\mathrm{PC}$ is highly malignant and invasive, resulting in poor prognosis [2]. Previous statistics for 2002-2008 from the US National Cancer Institute showed an overall 5 -year relative survival rate of $5.8 \%$ and a one-year

\footnotetext{
*Correspondence: chengllbj@163.com

'Department of Hepatobiliary Surgery, Air Force General Hospital of PLA, 30 Fucheng Road, Beijing 100142, China

Full list of author information is available at the end of the article
}

mortality rate of $90 \%$, with a median survival of less than 6 months $[3,4]$.

A number of studies [5-8] have showed that the development and progression of PC are linked with complex gene regulation, such as the inactivation of tumour suppressor genes, the activation of proto-oncogenes, abnormal regulation of cell proliferation and apoptosis adjustment disorders, and abnormal expression of growth factors and their receptors. In recent years, although targeted therapies in PC treatment have been gradually developed, the PC survival rate has not improved. Therefore, there is an urgent need for the identification of possible associated factors and novel therapeutic targets for PC. 
The SnoN gene, a member of the Ski family of protooncogenes that was originally identified based on sequence homology with $\mathrm{v}$-Ski, encodes an oncoprotein that can induce anchorage-independent growth of chicken and quail embryo fibroblasts when overexpressed [9-12]. SnoN is highly expressed in human cancer cells of the oesophagus, lung, vulva, stomach, ovary, pancreas, and breast [10,13-15]. SnoN overexpression in human cancer cells may result in gene amplification, transcriptional activation, and increased protein stability [14,16-19]. Moreover, SnoN was recently shown to silence the alpha fetoprotein gene, cooperating with p53 to negatively regulate transforming growth factor beta (TGF- $\beta$ ) signalling [19-21]. Although several previous studies investigated the effects of SnoN on the cell proliferation and apoptosis of ovarian, lung, breast, oesophageal, and colon cancers [22-26], the role SnoN plays in pancreatic cancer remain unknown.

In the present study, we established a pancreatic cancer cell line that stably silenced the $S n o N$ gene by siRNA, and investigated the effects of $S n o N$ on the proliferation and apoptosis of pancreatic cancer cells in vitro. This study may provide experimental evidence for gene therapy in PC.

\section{Methods}

\section{Ethical approval}

This study was approved by the Ethics Committee of Air Force General Hospital of PLA.

\section{Cell culture}

The SW1990 human pancreatic cancer cells were obtained from the Cell Bank of the Chinese Academy of Sciences (Shanghai, China) and cultured in Dulbecco's modified Eagle's medium (DMEM, HyClone, Logan, UT, USA) supplemented with $10 \%$ foetal bovine serum (FBS, HyClone, Logan, UT, USA), $100 \mathrm{U} / \mathrm{mL}$ penicillin and $100 \mu \mathrm{g} / \mathrm{mL}$ streptomycin. Cells were maintained in a $37^{\circ} \mathrm{C}$ humidified incubator containing $95 \%$ air and $5 \% \mathrm{CO}_{2}$.

\section{Reagents}

Opti-MEM medium and Lipofectamine 2000 (Lipo) were obtained from the Gibco-Invitrogen Corporation (USA). Trypsin was obtained from the HyClone Corporation (USA). The $\beta$-actin $\mathrm{mAb}$ was purchased from the Shanghai Kangcheng Biotechnology Corporation (Shanghai, China). The SnoN mAb was purchased from the Abcam Corporation (UK). The cDNA synthesis kit and TRIzol kit were purchased from Bao Biotechnology Corporation (Dalian, China). The RNA PCR kit was obtained from TaKaRa Corporation (Japan). The Western Blotting Detection system was obtained from Thermo Corporation (USA). The cell lysate and bicinchoninic acid (BCA) protein assay kit was purchased from Shanghai Biyuntian
Biotechnology Corporation (Shanghai, China). The Cell Counting Kit-8 was obtained from Dojindo Chemical Corporation (CCK-8, Japan). The Annexin V FITC/PI assay kit was purchased from Invitrogen Corporation (USA).

\section{SnoN siRNA sequences and PCR primers}

SnoN siRNAs, labelled by florescence FAM (FAM-siRNAs), and negative control siRNAs were synthesised by Shanghai Jima Biotechnology Co., Ltd. (Shanghai, China). For the SnoN siRNA-A, the sense strand was 5'-GGGCUUUG AAUCAGCUAAATT-3' and the antisense strand was 5'-U UUAGCUGAUUCAAAGCCCTT-3'. For the SnoN siRNA$\mathrm{B}$, the sense strand was 5'-GGCCCAGUUAAAGGAAAC UTT-3' and the antisense strand was 5'-AGUUUCCU UUAACUGGGCCTT-3'. For the SnoN siRNA-C, the sense strand was 5'-GAGGCAAGUAAGUCCAUAUTT-4' and the antisense strand was 5-AUAUGGACUUACUUGCC UCTT-3'. For the negative control siRNA, the sense strand was 5'-UUCUCCGAACGUGUCACGUTT-3' and the antisense strand was 5'-ACGUGACACGUUCGGAGAATT-3'. The SnoN primers were forward, 5'-AGAGACTCTGTT TGCCCCAAGT-3' and reverse, 5'-CATGCTAAACTTCT CCTTCATTTC-3'. The $\beta$-actin primers were forward, 5'-T TCTGTGGCATCCACGAAACT-3' and reverse, 5'-GAAG CATTTGCGGTGGACGAT-3’.

\section{siRNA transfection}

The pancreatic cancer cells were seeded at $1 \times 10^{5}$ cells/ well in 24-well plates 1 day before transfection. Medium without antibiotics was added to each well so that the cells grew to $50-70 \%$ confluence, when the transfection was conducted. The siRNA-Lipo mixture was prepared according to the manufacturer's instructions. To test the transfection efficiency of the FAM-siRNAs-Lipo mixture at different concentrations, $0,1,1.5$ and $2 \mu \mathrm{l}$ of Lipo were diluted with $50 \mu \mathrm{l}$ Opti-MEM, and $0,10,15$ and $20 \mu \mathrm{l}$ FAM-siRNAs, respectively, were added at $50 \mu \mathrm{l} /$ well and mixed. The $100 \mu \mathrm{l}$ mixture was added to $300 \mu \mathrm{l}$ of Opti-MEM including the pancreatic cancer cells. The concentrations of the four groups were $0 \mathrm{nmol} / \mathrm{L}$, $50 \mathrm{nmol} / \mathrm{L}, 75 \mathrm{nmol} / \mathrm{L}$, and $100 \mathrm{nmol} / \mathrm{L}$, respectively. Six hours later, the medium was replaced with DMEM supplemented with 10\% FBS. The expression of FAMsiRNAs was analysed with a flow cytometer.

\section{Quantitative RT-PCR}

Total RNA was extracted from cells using TRIzol reagent and reverse transcribed to cDNA using a first-strand cDNA synthesis kit according to the manufacturer's instructions. The efficiency of the SnoN siRNAs was screened using RT-PCR and real-time PCR. Real-time PCR was conducted on the Exicycler ${ }^{\text {Tm }} 96$ florescence quantitative instrument (Bioneer, Daejeon, Korea). PCR 
conditions and analysis were consistent with previously published methods [27].

\section{Western blotting}

SnoN protein expression was measured by Western blotting. $\beta$-actin was used as an internal control. Cells were lysed using cell lysis buffer, and the protein concentrations were quantified using the BCA assay method. Cellular proteins were dissolved in sample loading buffer and run on $7.5 \%$ sodium dodecyl sulphate-polyacrylamide gel electrophoresis (SDS-PAGE) gels (100 V, constant voltage, $60 \mathrm{~min})$. SnoN protein was electrotransferred onto PVDF membranes $\left(4^{\circ} \mathrm{C}, 280 \mathrm{~mA}, 60 \mathrm{~min}\right)$. The membranes were rinsed with PBS and blocked with $10 \%$ non-fat milk in PBS for $2 \mathrm{~h}$ at room temperature. Primary antibody was used at the following dilutions. After primary antibody incubation, membranes were rinsed in TBS-T wash buffer 3 times for $10 \mathrm{~min}$ each. Then, secondary antibody (1: 2,000 ) was incubated for $2 \mathrm{~h}$ at room temperature and rinsed in TBS-T wash buffer 3 times for 10 min each. Developed films were digitised by scanning, and the optical densities were analysed with the image software.

\section{Cell proliferation analysis}

Cell viability was measured using the CCK- 8 assay. Cells were seeded into 96-well plates at a density of $3 \times 10^{3}$ cells/well and placed in an incubator until the cells grew to confluence. Subsequently, $100 \mu \mathrm{l}$ of CCK- 8 solution was added at different time points $(0,24,48,72$, and $96 \mathrm{~h}$ ), and the samples were incubated at $37^{\circ} \mathrm{C}$ for $1.5 \mathrm{~h}$. The absorbance value of each well was measured at $450 \mathrm{~nm}$ using a microplate reader. Non-transfected cells were set as the blank control group. Cells treated with negative siRNA transfection were set as the negative control group.

\section{Analysis of cell apoptosis}

An annexin V FITC/PI assay kit was used to detect cell apoptosis. Cells were divided into three groups (blank control group, negative control group, and transfection group). At $50 \%-70 \%$ confluence, the cells were trypsinised and collected. After washing with PBS, $500 \mu \mathrm{l}$ of annexin-binding buffer was added to resuspend the cells. After the addition of $5 \mu \mathrm{l}$ Alexa-labelled annexin $\mathrm{V}$ and $1 \mu \mathrm{l} \mathrm{PI}$, the cells were incubated at room temperature in the dark for $15 \mathrm{~min}$ and then detected by flow cytometry.

\section{Statistical analysis}

Data are presented as the mean \pm standard deviation and were analysed using one-way analysis of variance (ANOVA) between groups using the SPSS 16.0 software. The differences among multiple mean values were evaluated using ANOVA. The differences between two mean values were estimated using an independent- samples $t$-test. The differences among the groups were analysed using the $\chi 2$ test. A $P<0.05$ was considered statistically significant.

\section{Results}

Transfection efficiency

The transfection efficiency was measured by flow cytometry. When the concentrations of the FAM-siRNA mixture were $0 \mathrm{nmol} / \mathrm{L}, 50 \mathrm{nmol} / \mathrm{L}, 75 \mathrm{nmol} / \mathrm{L}$, and $100 \mathrm{nmol} / \mathrm{L}$, the transfection efficiencies were $9.38 \%, 29.9 \%, 57.4 \%$, and $87.5 \%$, respectively. We found that the optimal transfection concentration was $100 \mathrm{nmol} / \mathrm{L}$.

\section{Silencing efficiency of SnoN siRNAs}

Three SnoN siRNA sequences were used to determine the silencing efficiency on SnoN mRNA expression in pancreatic cancer cells. The results after real-time PCR analysis showed little difference in band brightness between the five $\beta$-actin groups, which revealed that the RNA template for reverse transcription was equal in each group. No significant difference was observed between the blank and negative control groups. However, lower band brightness was evident in the three siRNA groups, compared with the blank or negative control groups $(\mathrm{P}<0.05)$. According to the ratio of the optical density values between the $\operatorname{SnoN}$ and $\beta$-actin bands, similar results were observed. The SnoN siRNA-C was found to have the most powerful silencing effect on the SnoN gene (Figure 1).

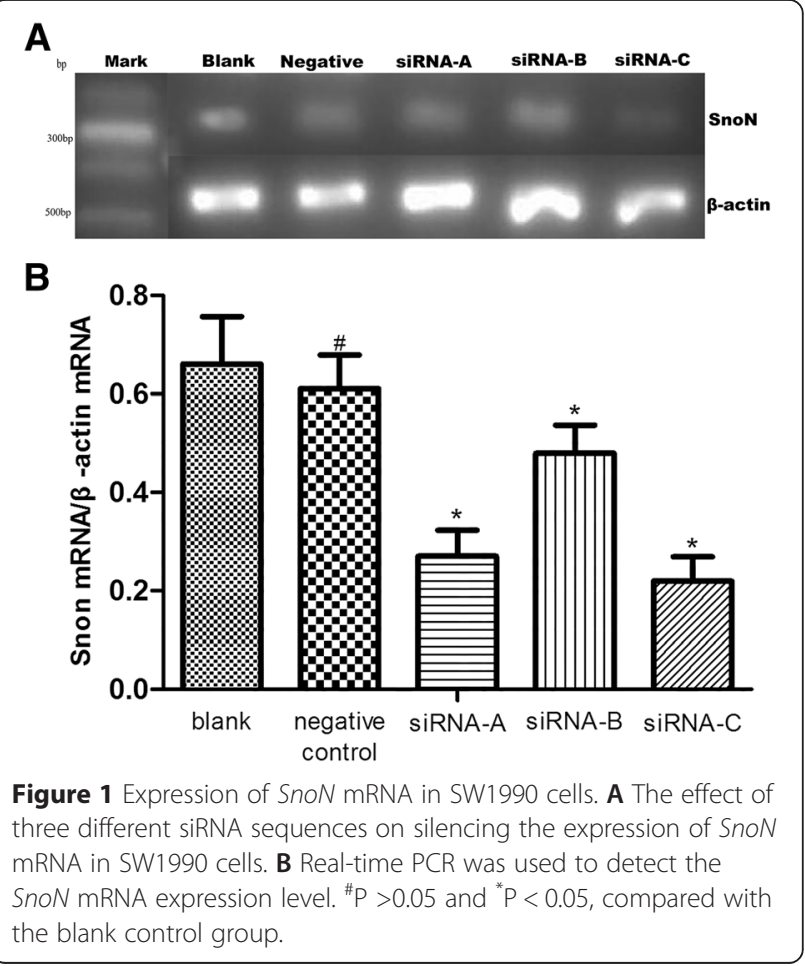




\section{Screening efficiency of $\mathrm{SnoN}$ protein expression using Western blotting}

The pooled results demonstrated that protein expression decreased in the three siRNA groups compared with the blank or negative control groups $(\mathrm{P}<0.05)$. SnoN siRNA-C had the most powerful inhibitory effect on SnoN protein expression (Figure 2).

\section{The effect of silencing $S n o N$ on cell proliferation}

The growth curve representing cell proliferation was drawn according to the results of the CCK-8 assay. The SnoN siRNA-C group was significantly decreased at each day after transfection $(\mathrm{P}<0.05)$. The lowest cell viability was observed at $3 \mathrm{~d}$ after transfection, and the recovery of cell viability started at $4 \mathrm{~d}$ after transfection (Figure 3).

\section{The effect of silencing $\mathrm{SnoN}$ on cell apoptosis}

The apoptotic cells increased after pancreatic cancer cells were transfected with SnoN siRNA-C $(\mathrm{P}<0.05)$. This was more obvious at $48 \mathrm{~h}$ after transfection. There was a significant difference between the SnoN siRNA group and the negative control group $(\mathrm{P}<0.05)$. There was a significant difference between the SnoN siRNA group and the blank control group $(\mathrm{P}<0.05)$. Moreover,

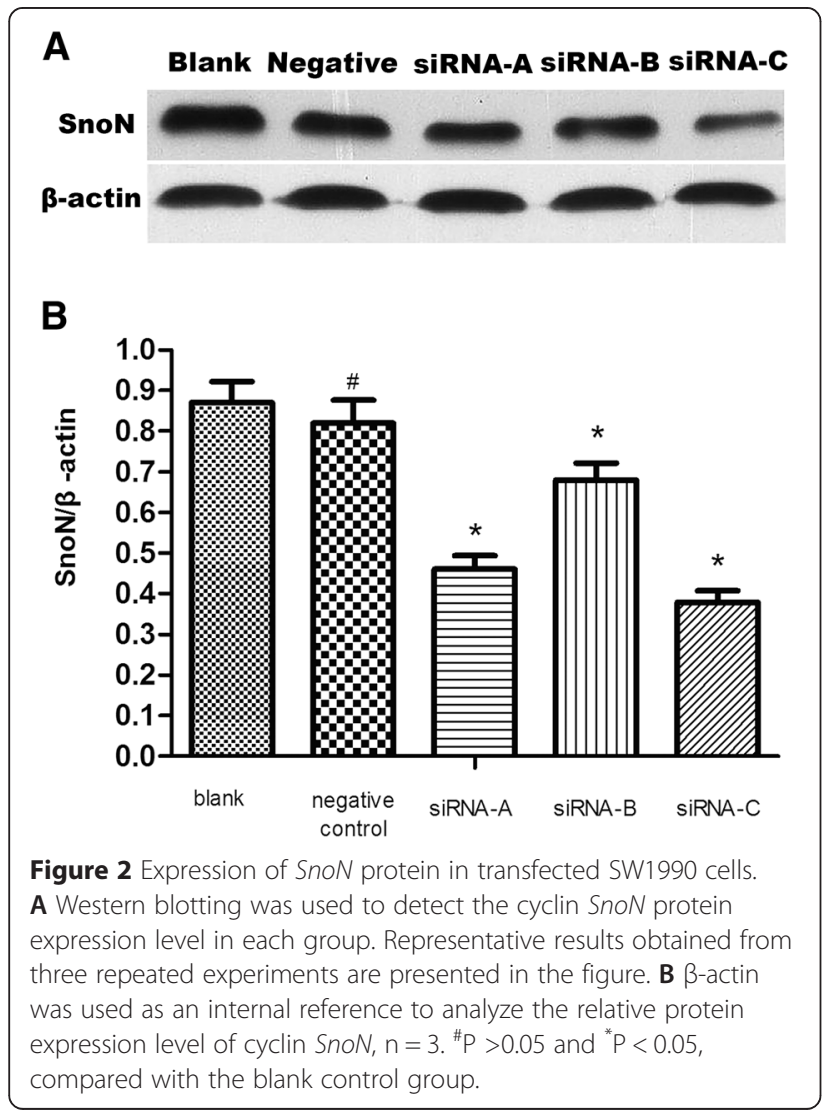

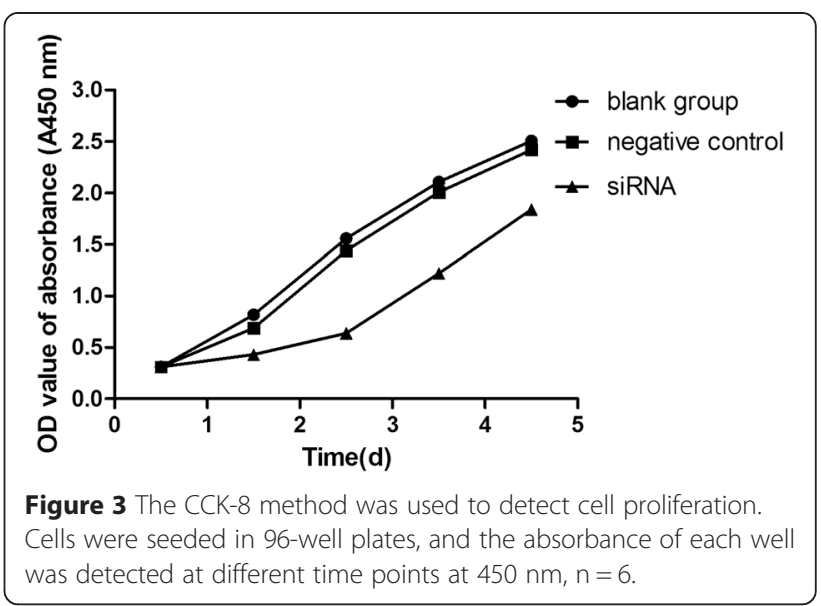

there were no significant differences between the negative control group (negative siRNA transfected cells) and the blank control group (non-transfected cells) (Figure 4, Table 1).

\section{Discussion}

The present work provides evidence of the importance of SnoN for cell growth in MPM. The transient SnoNsilencing caused a decrease in the proliferation rate of the pancreatic cancer cell line and an increase in the apoptosis rate.

Fewer than 5\% of patients with PC achieve 5-year survival, which reveals the poor prognosis of this cancer [28]. Therefore, to improve modern cancer therapy, numerous scholars have an ongoing interest in the identification of signalling pathways and genes that might play key roles in carcinogenesis and the development of resistance to anti-tumour drugs, with the hope of identifying putative biomarkers and/or therapeutic targets [29,30]. Applying molecular approaches, a large set of genes has been investigated for overexpression in pancreatic cancer [31-33]. However, more genes that may have an effect in the progression of PC need to be investigated.

The human SnoN gene is located at chromosome 3q26.2. SnoN is widely expressed in adult and embryonic cells. SnoN expression can be regulated at the level of gene amplification, transcriptional activation and protein stability. High expression of SnoN is found in many human cancers [22-26]. However, not all studies were consistent with upregulated $\mathrm{SnoN}$ expression in human cancers. While some studies reported an increase in SnoN RNA and protein in some cancer tissues and noted that this higher SnoN expression correlated with poor differentiation, deeper invasion and poor patient survival $[14,15,25]$, others detected a decrease in SnoN 


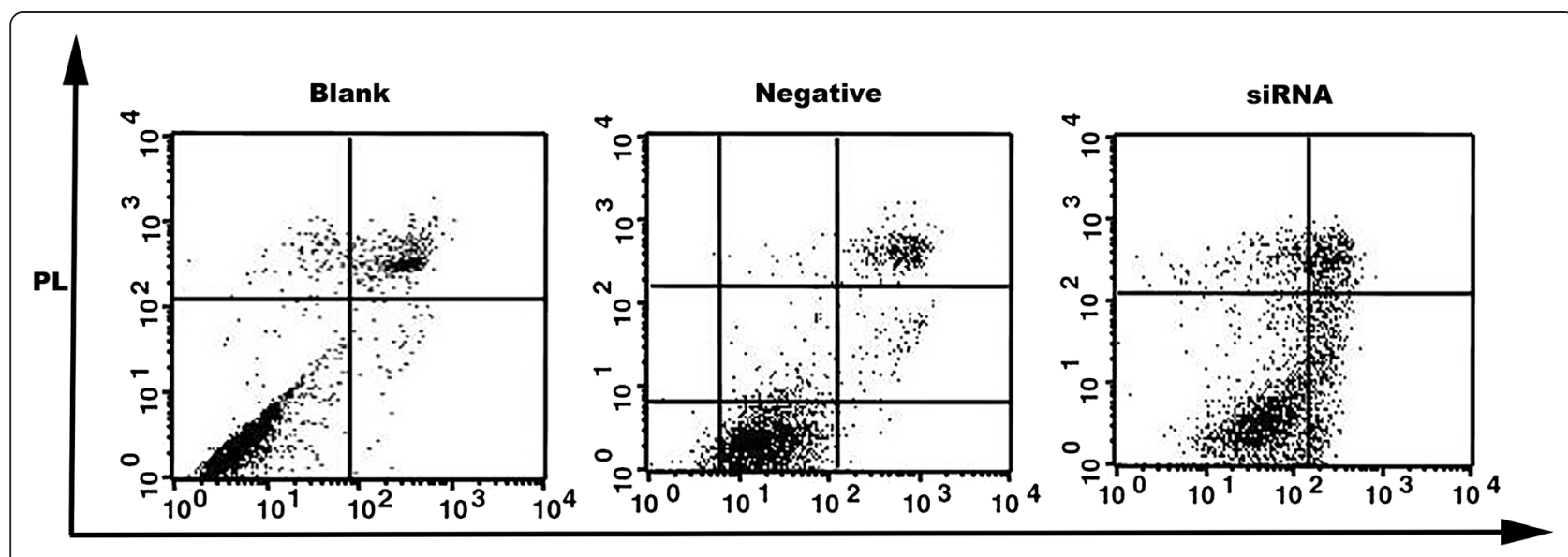

Annexin V-FITC

Figure 4 The effect of SnoN siRNA-C on apoptosis of SW1990 cells was tested by FCM.

expression in similar cancers, particularly in dysplastic and highly invasive cancers [34-36]. It appears that SnoN can also act as a negative regulator of tumour progression. In a recent study [21], SnoN was observed to cooperate with p53 in the silencing of the alpha fetoprotein gene, which is aberrantly overexpressed in liver cancer cells.

Moreover, SnoN and its structurally and functionally related protein Ski are negative regulators of TGF- $\beta$ induced transcription [37]. The level of SnoN is directly linked to its ability to repress TGF- $\beta$ signalling, but this activity may be cell-type specific [38]. SnoN has been reported to be both a tumour promoter and a tumour suppressor [39]. Over-expression of SnoN leads to resistance to TGF- $\beta$-induced growth arrest and formation of mammary tumours in cooperation with polyoma middle T-antigen [17]. Furthermore, previous studies have shown that $S n o N$ interacts directly

Table 1 The effect of SnoN-siRNA on apoptosis of PC cells $(\mathbf{n}=3)$

\begin{tabular}{lll}
\hline Group & Time (d) & Apoptosis (\%) \\
\hline Blank control & 24 & $0.26 \pm 0.27$ \\
& 48 & $0.67 \pm 1.38$ \\
Negative control & 72 & $1.77 \pm 1.54$ \\
& 24 & $0.29 \pm 0.31$ \\
SnoN-siRNA-C & 48 & $0.72 \pm 1.15$ \\
& 72 & $2.13 \pm 1.97$ \\
& 24 & $0.56 \pm 0.29^{*}$ \\
& 48 & $6.94 \pm 2.17^{*}$ \\
\hline
\end{tabular}

${ }^{*} \mathrm{P}<0.05$ vs. blank control. with Smad2, Smad3, and Smad4 and represses their ability to activate expression of TGF- $\beta$ target genes by disrupting the formation of an active heteromeric Smad complex, recruiting a transcriptional corepressor complex, and by blocking the interaction of transcriptional coactivators with Smad2 and Smad3 [40,41]. A number of investigations have indicated that PC is closely associated with the TGF- $\beta /$ Smad pathway, and Smad4 is inactivated in nearly $60 \%$ of PC [42]. However, the influence of SnoN gene expression on cell proliferation and apoptosis in human pancreatic cancer cells remains unclear.

Cell proliferation and apoptosis are important to the oncogenesis and chemotherapy resistance of pancreatic cancer cells [8]. In this study, we analysed the suppressive effect of PC cell proliferation and apoptosis by siRNA silencing of SnoN expression. The results showed that the proliferation of the SnoN-siRNA-transfected cells was slower than blank and negative group, suggesting a fundamental role for SnoN in the development of PC. Therefore, through silencing SnoN gene, development of PC might be alleviated. To date, this is the first study in which RNAi-mediated SnoN expression was shown to inhibit PC cell proliferation and induce apoptosis. This finding is consistent with the previous results that $S n o N$ promotes tumour proliferation and induces apoptosis in other cancers $[14,15,25]$. However, because the exact effect of SnoN expression on human cancers remains unclear, and multiple signalling pathways are thought to make important contributions to PC progression, further studies are necessary to clarify these complex mechanisms. Moreover, our study has a limitation, in that we only proved that RNAi inhibited SnoN expression in vitro. Therefore, further in vivo studies are needed to verify the effect and risk of SnoN knockdown by SnoN-siRNAs for PC therapy. 


\section{Conclusions}

In summary, our results revealed that the RNAi-mediated downregulation of SnoN effectively inhibited the proliferation of PC cells. Meanwhile, SnoN-siRNA also enhanced PC cell apoptosis. These findings indicated that $S n o N$ plays an important role in pancreatic cancer development, and might serve as a potential therapeutic target for pancreatic cancer. However, further in vivo studies are needed to clarify the influence of SnoN gene silencing by siRNA on pancreatic cancer therapy.

\section{Competing interests}

The authors declare that they have no competing interests.

\section{Authors' contributions}

$C L L$ performed the literature search, collected the data and drafted the manuscript. HZ, XXZ and CW performed the database setup and statistical analysis. YLK and HYZ helped to draft the manuscript. All authors have read and approved the final manuscript.

\section{Author details}

'Department of Hepatobiliary Surgery, Air Force General Hospital of PLA, 30 Fucheng Road, Beijing 100142, China. ²Department of Stomatology, Air Force General Hospital of PLA, Beijing, China.

\section{Received: 23 November 2014 Accepted: 7 April 2015}

\section{Published online: 18 April 2015}

\section{References}

1. Yadav D, Lowenfels AB. The epidemiology of pancreatitis and pancreatic cancer. Gastroenterology. 2013;144:1252-61.

2. Liu SX, Xia ZS, Zhong YQ. Gene therapy in pancreatic cancer. World J Gastroenterol. 2014;20:13343-68.

3. Laheru D, Biedrzycki B, Jaffee EM. Development of a cytokine-modified allogeneic whole cell pancreatic cancer vaccine. Methods Mol Biol. 2013;980:175-203.

4. Jemal A, Siegel R, Ward E, Hao Y, Xu J, Thun MJ. Cancer statistics, 2009. CA Cancer J Clin. 2009:59:225-49

5. Kodigepalli KM, Dutta PS, Bauckman KA, Nanjundan M. SnoN/SkiL expression is modulated via arsenic trioxide-induced activation of the PI3K/AKT pathway in ovarian cancer cells. FEBS Lett. 2013;587:5-16.

6. Xu K, Chen Z, Qin C, Song X. miR-7 inhibits colorectal cancer cell proliferation and induces apoptosis by targeting XRCC2. Onco Targets Ther. 2014;7:325-32.

7. Song SD, Zhou J, Zhou J, Zhao H, Cen JN, Li DC. MicroRNA-375 targets the 3-phosphoinositide-dependent protein kinase-1 gene in pancreatic carcinoma. Oncol Lett. 2013;6:953-9.

8. Li J, Hu GH, Kong FJ, Wu KM, He B, Song K, et al. Reduced STMN1 expression induced by RNA interference inhibits the bioactivity of pancreatic cancer cell line Panc-1. Neoplasma. 2014;61:144-52.

9. Boyer PL, Colmenares C, Stavnezer E, Hughes SH. Sequence and biological activity of chicken SnoN cDNA clones. Oncogene. 1993;8:457-66.

10. Nomura N, Sasamoto S, Ishii S, Date T, Matsui M, Ishizaki R. Isolation of human CDNA clones of ski and the ski-related gene, sno. Nucleic Acids Res. 1989:17:5489-500.

11. Pearson-White S. Snol, a novel alternatively spliced isoform of the ski protooncogene homolog, sno. Nucleic Acids Res. 1993;21:4632-8.

12. Pearson-White $S$, Crittenden R. Proto-oncogene Sno expression, alternative isoforms and immediate early serum response. Nucleic Acids Res. 1997:25:2930-7.

13. Jahchan NS, Ouyang G, Luo K. Expression profiles of SnoN in normal and cancerous human tissues support its tumor suppressor role in human cancer. PLoS One. 2013;8:e55794.

14. Imoto I, Pimkhaokham A, Fukuda $Y$, Yang ZQ, Shimada $Y$, Nomura $N$, et al. $\mathrm{SNO}$ is a probable target for gene amplification at $3 q 26$ in squamous-cell carcinomas of the esophagus. Biochem Biophys Res Commun. 2001;286:559-65.

15. Zhang F, Lundin M, Ristimaki A, Heikkila P, Lundin J, Isola J, et al. Ski-related novel protein $\mathrm{N}(\mathrm{SnON})$, a negative controller of transforming growth factor-beta signaling, is a prognostic marker in estrogen receptor-positive breast carcinomas. Cancer Res. 2003:63:5005-10.

16. Bonni S, Wang HR, Causing CG, Kavsak P, Stroschein SL, Luo K, et al. TGF-beta induces assembly of a Smad2-Smurf2 ubiquitin ligase complex that targets SnoN for degradation. Nat Cell Biol. 2001;3:587-95.

17. Edmiston JS, Yeudall WA, Chung TD, Lebman DA. Inability of transforming growth factor-beta to cause $S n o N$ degradation leads to resistance to transforming growth factor-beta-induced growth arrest in esophageal cancer cells. Cancer Res. 2005;65:4782-8.

18. Stroschein SL, Bonni S, Wrana JL, Luo K. Smad3 recruits the anaphasepromoting complex for ubiquitination and degradation of SnoN. Genes Dev. 2001;15:2822-36.

19. Stroschein SL, Wang W, Zhou S, Zhou Q, Luo K. Negative feedback regulation of TGF-beta signaling by the $S$ noN oncoprotein. Science. 1999:286:771-4

20. Sun $Y$, Liu $X, N g$-Eaton E, Lodish HF, Weinberg RA. SnoN and Ski protooncoproteins are rapidly degraded in response to transforming growth factor beta signaling. Proc Natl Acad Sci U S A. 1999:96:12442-7.

21. Wilkinson DS, Ogden SK, Stratton SA, Piechan JL, Nguyen TT, Smulian GA, et al. A direct intersection between p53 and transforming growth factor beta pathways targets chromatin modification and transcription repression of the alpha-fetoprotein gene. Mol Cell Biol. 2005:25:1200-12.

22. Deheuninck J, Luo K. Ski and SnoN, potent negative regulators of TGF-beta signaling. Cell Res. 2009;19:47-57.

23. Jahchan NS, Luo K. SnoN in mammalian development, function and diseases. Curr Opin Pharmacol. 2010;10:670-5.

24. Zhu Q, Krakowski AR, Dunham EE, Wang L, Bandyopadhyay A, Berdeaux R, et al. Dual role of SnoN in mammalian tumorigenesis. Mol Cell Biol. 2007:27:324-39.

25. Akagi I, Miyashita M, Makino H, Nomura T, Hagiwara N, Takahashi K, et al SnoN overexpression is predictive of poor survival in patients with esophageal squamous cell carcinoma. Ann Surg Oncol. 2008;15:2965-75.

26. Nanjundan M, Cheng KW, Zhang F, Lahad J, Kuo WL, Schmandt R, et al. Overexpression of SnoN/SkiL, amplified at the 3q26.2 locus, in ovarian cancers: a role in ovarian pathogenesis. Mol Oncol. 2008:2:164-81.

27. Wang N, Wei H, Yin D, Lu Y, Zhang Y, Jiang D, et al. Cyclin D1b overexpression inhibits cell proliferation and induces cell apoptosis in cervical cancer cells. in vitro and in vivo. Int J Clin Exp Pathol. 2014;7:4016-23.

28. Rosenberg L. Pancreatic cancer: a review of emerging therapies. Drugs. 2000;59:1071-89.

29. Ouaissi M, Silvy F, Loncle C, Ferraz Da Silva D, Martins Abreu C, Martinez E, et al. Further characterization of HDAC and SIRT gene expression patterns in pancreatic cancer and their relation to disease outcome. PLoS One. 2014:9:e108520

30. Hruban RH, Goggins M, Parsons J, Kern SE. Progression model for pancreatic cancer. Clin Cancer Res. 2000;6:2969-72.

31. Ouaissi M, Sielezneff I, Silvestre R, Sastre B, Bernard JP, Lafontaine JS, et al. High histone deacetylase 7 (HDAC7) expression is significantly associated with adenocarcinomas of the pancreas. Ann Surg Oncol. 2008;15:2318-28.

32. Gress TM, Muller-Pillasch F, Geng M, Zimmerhackl F, Zehetner G, Friess $H$, et al. A pancreatic cancer-specific expression profile. Oncogene. 1996;13:1819-30

33. Crnogorac-Jurcevic T, Missiaglia E, Blaveri E, Gangeswaran R, Jones M, Terris $B$, et al. Molecular alterations in pancreatic carcinoma: expression profiling shows that dysregulated expression of S100 genes is highly prevalent. J Pathol. 2003;201:63-74.

34. Zhang $X$, Egawa $K$, Xie $Y$, Ihn $H$. The expression of SnoN in normal human skin and cutaneous keratinous neoplasms. Int J Dermatol. 2009;48:579-83.

35. Villanacci V, Bellone G, Battaglia E, Rossi E, Carbone A, Prati A, et al. Ski/ SnoN expression in the sequence metaplasia-dysplasia-adenocarcinoma of Barrett's esophagus. Hum Pathol. 2008;39:403-9.

36. Chia JA, Simms LA, Cozzi SJ, Young J, Jass JR, Walsh MD, et al. SnoN expression is differently regulated in microsatellite unstable compared with microsatellite stable colorectal cancers. BMC Cancer. 2006;6:252.

37. Band AM, Laiho M. SnoN oncoprotein enhances estrogen receptor-alpha transcriptional activity. Cell Signal. 2012;24:922-30.

38. Sarker KP, Wilson SM, Bonni S. SnoN is a cell type-specific mediator of transforming growth factor-beta responses. J Biol Chem. 2005;280:13037-46.

39. Lamouille $S$, Derynck R. Oncogene and tumour suppressor: the two faces of SnoN. EMBO J. 2009:28:3459-60. 
40. Akiyoshi S, Inoue H, Hanai J, Kusanagi K, Nemoto N, Miyazono K, et al. c-Sk acts as a transcriptional co-repressor in transforming growth factor-beta signaling through interaction with smads. J Biol Chem. 1999;274:35269-77.

41. Luo K, Stroschein SL, Wang W, Chen D, Martens E, Zhou S, et al. The Ski oncoprotein interacts with the Smad proteins to repress TGFbeta signaling. Genes Dev. 1999;13:2196-206.

42. Truty MJ, Urrutia R. Basics of TGF-beta and pancreatic cancer. Pancreatology. 2007; $7: 423-35$

Submit your next manuscript to BioMed Central and take full advantage of:

- Convenient online submission

- Thorough peer review

- No space constraints or color figure charges

- Immediate publication on acceptance

- Inclusion in PubMed, CAS, Scopus and Google Scholar

- Research which is freely available for redistribution 